Louisiana State University

LSU Digital Commons

$11-2-2004$

\title{
Phosphonoformate: A minimal transition state analogue inhibitor of the fosfomycin resistance protein, FosA
}

\author{
Rachel E. Rigsby \\ Vanderbilt University School of Medicine \\ Chris L. Rife \\ Vanderbilt University School of Medicine \\ Kerry L. Fillgrove \\ Vanderbilt University School of Medicine \\ Marcia E. Newcomer \\ Louisiana State University \\ Richard N. Armstrong \\ Vanderbilt University School of Medicine
}

Follow this and additional works at: https://digitalcommons.Isu.edu/biosci_pubs

\section{Recommended Citation}

Rigsby, R., Rife, C., Fillgrove, K., Newcomer, M., \& Armstrong, R. (2004). Phosphonoformate: A minimal transition state analogue inhibitor of the fosfomycin resistance protein, FosA. Biochemistry, 43 (43), 13666-13673. https://doi.org/10.1021/bi048767h 


\title{
Phosphonoformate: A Minimal Transition State Analogue Inhibitor of the Fosfomycin Resistance Protein, FosA $A^{\dagger,+}$
}

\author{
Rachel E. Rigsby, ${ }^{\S}$ Chris L. Rife, ${ }^{\S, \|}$ Kerry L. Fillgrove, ${ }^{\S}$ Marcia E. Newcomer, ${ }^{\perp}$ and Richard N. Armstrong*, \\ Departments of Chemistry and Biochemistry, Center in Molecular Toxicology, Vanderbilt University School of Medicine, \\ Nashville, Tennessee 37232-0146, and Departments of Biological Sciences and Chemistry, Louisiana State University, \\ Baton Rouge, Louisiana 70803
}

Received June 14, 2004; Revised Manuscript Received August 21, 2004

\begin{abstract}
Fosfomycin [(1R,2S)-epoxypropylphosphonic acid] is a simple phosphonate found to have antibacterial activity against both Gram-positive and Gram-negative microorganisms. Early resistance to the clinical use of the antibiotic was linked to a plasmid-encoded resistance protein, FosA, that catalyzes the addition of glutathione to the oxirane ring, rendering the antibiotic inactive. Subsequent studies led to the discovery of a genomically encoded homologue in the pathogen Pseudomonas aeruginosa. The proteins are $\mathrm{Mn}$ (II)-dependent enzymes where the metal is proposed to act as a Lewis acid stabilizing the negative charge that develops on the oxirane oxygen in the transition state. Several simple phosphonates, including the antiviral compound phosphonoformate $\left(K_{\mathrm{i}}=0.4 \pm 0.1 \mu \mathrm{M}, K_{\mathrm{d}} \approx 0.2 \mu \mathrm{M}\right)$, are shown to be inhibitors of FosA. The crystal structure of FosA from $P$. aeruginosa with phosphonoformate bound in the active site has been determined at $0.95 \AA$ resolution and reveals that the inhibitor forms a five-coordinate complex with the $\mathrm{Mn}(\mathrm{II})$ center with a geometry similar to that proposed for the transition state of the reaction. Binding studies show that phosphonoformate has a near-diffusion-controlled on rate $\left(k_{\mathrm{on}} \approx 10^{7}-10^{8} \mathrm{M}^{-1}\right.$ $\left.\mathrm{s}^{-1}\right)$ and an off rate $\left(k_{\mathrm{off}}=5 \mathrm{~s}^{-1}\right)$ that is slower than that for fosfomycin $\left(k_{\mathrm{off}}=30 \mathrm{~s}^{-1}\right)$. Taken together, these data suggest that the FosA-catalyzed reaction has a very early transition state and phosphonoformate acts as a minimal transition state analogue inhibitor.
\end{abstract}

Fosfomycin $[(1 R, 2 S)$-epoxypropylphosphonic acid, 1] is a natural product with broad-spectrum antimicrobial activity against both Gram-positive and Gram-negative microorganisms $(1,2)$. The drug inhibits the enzyme UDP- $N$-acetylglucosamine-3-enolpyruvyltransferase (MurA), which catalyzes the first committed step in microbial cell-wall biosynthesis (3-5). Properly formulated, the drug has good bioavailability, is eliminated virtually unmetabolized via renal excretion, and exhibits very low toxicity with few side effects. The drug is currently used in a single-dose oral treatment for acute uncomplicated lower urinary tract infection $(6,7)$. It has also been suggested that large doses of fosfomycin are effective against vancomycin-resistant enterococci (8).

Shortly after introduction of fosfomycin in the clinic, a plasmid-mediated resistance to the antibiotic was observed in clinical isolates from patients treated with the drug (911). Subsequent investigations established that the resistance gene encoded a $16 \mathrm{kDa}$ polypeptide (FosA) that catalyzed

Supported by Grants R01 AI42756, P30 ES00267, T32 ES07028, and T32 GM08320 from the National Institutes of Health.

Atomic coordinates and structure factors for the inhibitor and sulfate complexes have been deposited in the RCSB Protein Data Bank as entries 1NKI (phosphonoformate) and 1NNR (sulfate).

* To whom correspondence should be addressed. E-mail: r.armstrong@ vanderbilt.edu. Fax: (615) 343-2921. Telephone: (615) 343-2920.

$\S$ Vanderbilt University School of Medicine.

" Present address: Stanford University, Stanford, CA 94305.

${ }^{\perp}$ Louisiana State University.
Scheme 1
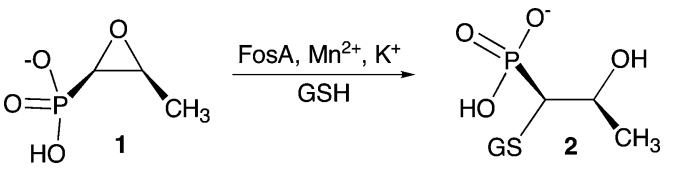

the addition of glutathione $(\mathrm{GSH})^{1}$ to the antibiotic (Scheme $1)$, rendering it inactive $(12,13)$. Fos $\mathrm{A}$ is a $\mathrm{Mn}(\mathrm{II})$ - and $\mathrm{K}^{+}$dependent homodimeric enzyme $(14-16)$ that belongs to the vicinal oxygen chelate (VOC) superfamily of metalloenzymes that includes glyoxalase I, methylmalonyl-CoA epimerase, and extradioldioxygenases $(17,18)$. Close relatives of FosA also appear in microbial genomes and may be responsible for intrinsic resistance of many microorganisms to the antibiotic. For example, the PA1129 gene from Pseudomonas aeruginosa encodes a FosA protein that has catalytic properties very similar to those of the plasmidencoded enzyme (19). In addition, the $y n d N$ gene from Bacillus subtilis has been demonstrated to confer resistance to the antibiotic by catalyzing the addition of L-cysteine to the oxirane ring in a $\mathrm{Mg}^{2+}$-dependent reaction (20).

The FosA enzyme is a dimer composed of paired $\beta \alpha \beta \beta \beta$ motifs that form a cupped-shaped metal ion binding site as illustrated in Figure 1 (19). The two subunits have a domain-

\footnotetext{
${ }^{1}$ Abbreviations: GSH, reduced glutathione; VOC, vicinal oxygen chelate; HEPES, 4-(2-hydroxyethyl)piperazine-1-ethanesulfonic acid; TMA, tetramethylammonium; PEP, pentaerythritol propoxylate; MES, 2-morpholinoethanesulfonic acid.
} 


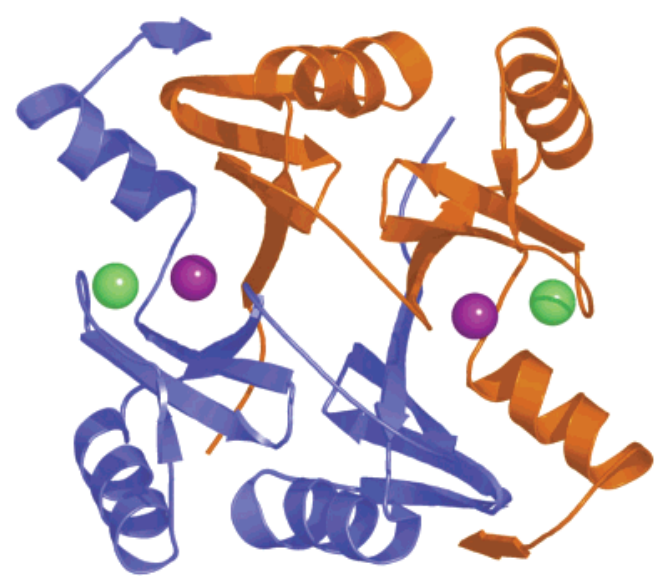

FIGURE 1: Ribbon diagram of the structure of FosA (PA1129) from $P$. aeruginosa taken from ref 19 . The $\mathrm{Mn}(\mathrm{II})$ and $\mathrm{K}^{+}$ions are illustrated as purple and green spheres, respectively. The image was created with PyMOL (21).
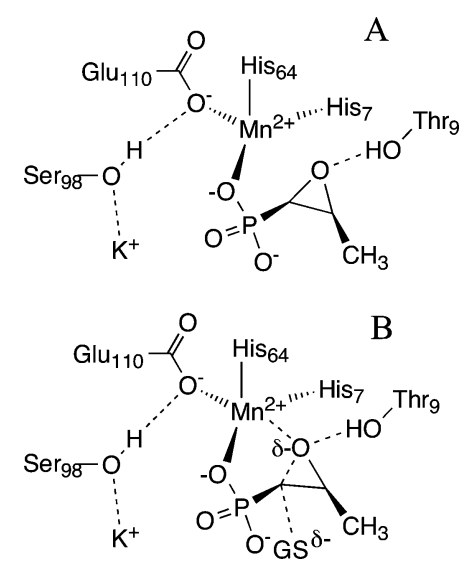

FIGURE 2: (A) Schematic of the interaction of fosfomycin with the $\mathrm{Mn}$ (II) center of FosA derived from the crystal structure at a resolution of $1.19 \AA$ (19). The metal coordination is formally fourcoordinate with a highly distorted tetrahedral geometry. The distance between the oxirane oxygen and Mn(II) is $2.35 \AA$. (B) Proposed transition state for the addition of $\mathrm{GS}^{-}$to fosfomycin. The metal is envisioned to approach a five-coordinate trigonal bipyramidal geometry.

swapped arrangement so that each $\mathrm{Mn}(\mathrm{II})$ binding site is formed from $\beta \alpha \beta \beta \beta$ motifs from opposing subunits. The $\mathrm{K}^{+}$ ion is accommodated in a loop located $6.5 \AA$ from the $\mathrm{Mn}(\mathrm{II})$ center.

Numerous lines of evidence suggest that the $\mathrm{Mn}(\mathrm{II})$ center of FosA participates directly in the catalytic mechanism (14, $16,19,22,23)$. The single most convincing piece of evidence is the crystal structure of the substrate complex, which shows that the phosphonyl group of fosfomycin is coordinated to the metal positioning the oxirane oxygen just outside the inner coordination sphere as illustrated in Figure 2. The structure clearly suggests that the $\mathrm{Mn}$ (II) ion acts as a Lewis acid in facilitating the addition of $\mathrm{GSH}$ at $\mathrm{C}-1$. In the substrate-bound ground state, the metal ion has a formal fourcoordinate geometry that is expected to become fivecoordinate as the carbon-oxygen bond begins to break in the transition state (Figure 2B).

Plasmid-encoded and genomically encoded fosfomycin resistance proteins constitute a serious impediment to the efficacy of the antibiotic toward pathogenic microorganisms. The development of inhibitors of these resistance proteins represents an opportunity to expand the clinical utility of the drug. In this paper, we present evidence that the antiviral compound, phosphonoformate (3), is an effective inhibitor of FosA and superior to other simple phosphonates. The kinetic and spectroscopic properties of the inhibitor complex, as well as its crystal structure determined at a resolution of $0.95 \AA$, suggest that $\mathbf{3}$ functions as a minimal transition state inhibitor of FosA.

\section{EXPERIMENTAL PROCEDURES}

Materials. Glutathione, glutathione sulfonate, and protease inhibitor solution were purchased from Sigma (St. Louis, MO). The plasmid-encoded FosA and the FosA from $P$. aeruginosa were expressed and purified as previously described $(14,19)$. Acetonitrile (HPLC grade) was purchased from EM Science (Gibbstown, NJ). PfuTurbo DNA polymerase was purchased from Stratagene (La Jolla, CA) and Quick T4 DNA Ligase from New England BioLabs Inc. (Beverly, MA). Phosphonoacetic acid, 2-carboxyethylphosphonic acid, and tris(trimethylsilyl) phosphite were from Aldrich (Milwaukee, WI). Acetyl chloride and diethyl ether were from Fisher. Triethylphosphonoformate was from Avocado Research Chemicals Ltd. AG1-X8 resin was from Bio-Rad. All materials were used without further purification. All the solutions were prepared and used on the same day.

Synthesis of Phosphonoformate. Phosphonoformate (3) was prepared from triethylphosphonoformate by a previously reported method [Jakupovic, E., et al. (1997) U.S. Patent 5591889]. Triethylphosphonoformate (10 g, $48 \mathrm{mmol})$ was added to a solution of $11.42 \mathrm{~g}(285 \mathrm{mmol})$ of sodium hydroxide in $90 \mathrm{~mL}$ of water at $50{ }^{\circ} \mathrm{C}$. The solution was heated to $90{ }^{\circ} \mathrm{C}$. After being refluxed for $1 \mathrm{~h}$, the reaction mixture was cooled to $20^{\circ} \mathrm{C}$. Phosphonoformate was then filtered from the reaction mixture using a Buchner funnel fitted with Whatman \#1 filter paper. The product was recrystallized from water and lyophilized to dryness.

Synthesis of Acetylphosphonate. Acetylphosphonic acid was synthesized following methods previously described (24, 25). Tris(trimethylsilyl) phosphite was slowly added to a 2-fold excess of acetyl chloride in a flask immersed in an ice/EtOH bath. The mixture was stirred for at least $2 \mathrm{~h}$ on ice and then stirred at room temperature overnight. After removal of the volatile silane products, the $\mathrm{pH}$ of the solution was adjusted to 4 with $\mathrm{NaOH}$. The reaction mixture was extracted with diethyl ether several times. The aqueous layer containing the product was then taken to dryness by lyophilization: ${ }^{1} \mathrm{H}$ NMR $\left(300.1 \mathrm{MHz}, \mathrm{D}_{2} \mathrm{O}\right) \delta 2.22\left(\mathrm{~d}, J_{\mathrm{PCH}}\right.$ $=3.72 \mathrm{~Hz}) ;{ }^{13} \mathrm{C} \mathrm{NMR}\left(75.5 \mathrm{MHz}, \mathrm{D}_{2} \mathrm{O}\right) \delta 30.6\left(\mathrm{~d}, J_{\mathrm{CP}}=\right.$ $43.8 \mathrm{~Hz}), 228.6$ (d, $\left.J_{\mathrm{CCP}}=157.6 \mathrm{~Hz}\right)$.

Enzyme Assay and Inhibition. Enzyme assays were carried out as previously described (14). In a typical reaction mixture, the enzyme $(60-150 \mathrm{nM})$ was incubated with 100 $\mathrm{mM} \mathrm{KCl}, 50 \mu \mathrm{M} \mathrm{MnCl}_{2}$, and $15 \mathrm{mM} \mathrm{GSH}$ in $20 \mathrm{mM}$ HEPES/TMA ( $\mathrm{pH} \mathrm{8.0)}$ at $25^{\circ} \mathrm{C}$ in the presence of $1,2,3$, or $4 \mathrm{mM}$ disodium fosfomycin and varying concentrations of phosphonoformate, acetylphosphonic acid, phosphonoacetic acid, or 2-carboxyethylphosphonic acid. Reactions were quenched; $1.0 \mathrm{mM}$ valine was added as an internal standard, and the mixture was reacted with the Waters AccQFluor reagent and analyzed by reversed-phase HPLC. Inhibition data were analyzed as a Dixon plot (1/v vs [I]) to determine $K_{\mathrm{I}}(26)$. 
Titration of FosA with 1 and 3 . A solution of $0.1 \mu \mathrm{M}$ FosA in the presence of $50 \mu \mathrm{M} \mathrm{MnCl}_{2}$ was prepared in $20 \mathrm{mM}$ TMA/HEPES (pH 8.0) containing $100 \mathrm{mM} \mathrm{KCl}$ which had been filtered through a $0.2 \mu \mathrm{M}$ filter. A solution of $50 \mu \mathrm{M}$ $\mathrm{MnCl}_{2}$ in buffer was similarly prepared. Phosphonates were added to both solutions incrementally while monitoring the change in fluorescence. Titration measurements were made in triplicate on a SPEX Fluorolog-3 spectrofluorimeter (Jobin Yvon Horiba, Edison, NJ) in the constant-wavelength mode. Solutions were excited at $275 \mathrm{~nm}$ (3 mm slit width), and emission measurements were taken at $330 \mathrm{~nm}(2 \mathrm{~mm}$ slit width). After data were corrected for fluorescence of the buffer solution, data were averaged and fit as the absolute value of the change in fluorescence to eq 1

$|\Delta F|=$
$-\left[\frac{-\left(K_{\mathrm{d}}+[\mathrm{P}]+F_{\text {max }}\right)+\sqrt{\left(K_{\mathrm{d}}+[\mathrm{P}]+F_{\text {max }}\right)^{2}-4[\mathrm{P}] F_{\text {max }}}}{2}\right]$

Stopped-Flow Analysis of Binding Kinetics. The PA1129 FosA incubated with $\mathrm{MnCl}_{2}$ and $\mathbf{3}$ in $20 \mathrm{mM}$ HEPES/TMA (pH 8.0) was mixed with varying concentrations of fosfomycin in an Applied Photophysics SX17 stopped-flow spectrometer in absorbance mode. The change in absorbance at $245 \mathrm{~nm}$ was monitored as a function of time; 1000 data points were collected in $100 \mathrm{~ms}$ using the oversampling method. Concentrations in the observation cell were as follows: $5 \mu \mathrm{M}$ FosA, $50 \mu \mathrm{M} \mathrm{MnCl}_{2}, 100 \mathrm{mM} \mathrm{K}^{+}, 25 \mu \mathrm{M}$ $\mathbf{2}$, and 5, 10, 15, and $20 \mathrm{mM} \mathbf{1}$. Data were fitted to a singleexponential, floating end point equation using the instrument software to obtain $k_{\mathrm{obs}}$. The first $2 \mathrm{~ms}$ of data were omitted from the data analysis. The off rate for $\mathbf{1}$ was measured in a similar manner by trapping with $\mathbf{3}$.

Crystallographic Data Collection. Crystals of the FosA enzyme from $P$. aeruginosa were obtained at $22{ }^{\circ} \mathrm{C}$ from $40 \%$ pentaerythritol propoxylate 629 (PEP629) and $80 \mathrm{mM}$ $\mathrm{K}_{2} \mathrm{HPO}_{4}(\mathrm{pH} 7.0)$ in the presence $0.8 \mathrm{mM} \mathrm{Mn}^{2+}$ and $0.8 \mathrm{mM}$ fosfomycin as previously described (19). The crystals diffracted quite well but contained phosphate bound in the active site. The crystals were transferred to a new drop containing 40\% PEP629, $40 \mathrm{mM}$ potassium chloride, $40 \mathrm{mM}$ phosphonoformate ( $\mathrm{pH} 7.0$ ), and $0.8 \mathrm{mM}$ manganese(II) chloride. These crystals were allowed to soak for $1 \mathrm{~h}$ before they were mounted for screening at Vanderbilt with an RU-200H rotating anode source and a RaxisIV image plate. All crystals were frozen directly from the drop, as the mother liquor provided sufficient cryroprotection against the formation of ice. The incubation with inhibitor had no apparent effect on the resolution.

A high-resolution data set was collected at $-180{ }^{\circ} \mathrm{C}$ with an ADSC Quantum 4 detector at the BioCARS beamline 14 $\mathrm{BMC}$ at the Advanced Photon Source (Argonne National Laboratory, Argonne, IL). The data were collected in two passes, each containing $100,1^{\circ}$ oscillation images that covered the same range of crystal orientation. The highresolution reflections were collected in the first pass with a crystal-to-detector distance of $70 \mathrm{~mm}$ and an exposure time of $20 \mathrm{~s}$. The second pass, to obtain the lower-resolution reflections, was taken with a crystal-to-detector distance of $150 \mathrm{~mm}$ and an exposure time of $2 \mathrm{~s}$. The data were scaled and processed with SCALEPACK and DENZO (27). A

\begin{tabular}{|c|c|c|}
\hline & $\begin{array}{l}\text { phosphonoformate } \\
\text { (1NKI) }\end{array}$ & $\begin{array}{l}\text { sulfate } \\
(1 \mathrm{NNR})\end{array}$ \\
\hline \multicolumn{3}{|c|}{ Diffraction Data } \\
\hline space group & $P 2_{1} 2_{1} 2_{1}$ & $P 2{ }_{1} 2_{1} 2_{1}$ \\
\hline cell parameters $a, b, c(\AA)$ & $\begin{array}{l}54.79,66.97 \\
77.00\end{array}$ & $\begin{array}{l}44.93,64.52, \\
78.83\end{array}$ \\
\hline $\begin{array}{l}\text { wavelength of data } \\
\text { collection }(\AA)\end{array}$ & 0.9000 & 1.54 \\
\hline highest-resolution shell ( & $0.98-0.95$ & $2.33-2.25$ \\
\hline $\begin{array}{l}R_{\text {merge }}(\%) \\
\quad \text { (overall/high-resolution shell) }\end{array}$ & $5.8 / 35.8$ & $8.9 / 32.0$ \\
\hline $\begin{array}{l}\text { completeness }(\%) \\
\text { (overall/high-resolution shell) }\end{array}$ & $91.3 / 46.8$ & $89.7 / 60.3$ \\
\hline redundancy & 8.4 & 8.0 \\
\hline$\langle I / \sigma I\rangle$ & $26 / 2.3$ & $12.5 / 3.1$ \\
\hline \multicolumn{3}{|c|}{ Refinement } \\
\hline refinement program & SHELXL & REFMAC \\
\hline resolution limits ( $\mathrm{A})$ & $30.0-0.95$ & $20.0-2.25$ \\
\hline no. of unique data & 154452 & 10221 \\
\hline$R_{\text {work }}$ & 0.132 & 0.193 \\
\hline$R_{\text {free }}$ & 0.161 & 0.268 \\
\hline content of asymmetric unit & intact dimer & intact dimer \\
\hline no. of residues per monomer & 134 & 134 \\
\hline no. of inhibitors per monomer & 1 & \\
\hline \multicolumn{3}{|l|}{ no. of non- $\mathrm{H}$ atoms } \\
\hline protein & 2169 & 2126 \\
\hline solvent & 419 & 90 \\
\hline other & 18 & 12 \\
\hline \multicolumn{3}{|l|}{ deviations } \\
\hline bond distances $(\AA)$ & 0.022 & 0.022 \\
\hline bond angles (deg) & 2.13 & 1.81 \\
\hline $\begin{array}{l}\text { Ramachandran analysis } \\
\text { [allowed }+ \text { favored }(\%)]\end{array}$ & 100 & 100 \\
\hline \multicolumn{3}{|l|}{ average $B$ dactors $\left(\AA^{2}\right)$} \\
\hline protein & 14.8 & 32.9 \\
\hline $\mathrm{Mn}$ & 8.93 & 35.1 \\
\hline $\mathrm{K}$ & 10.7 & - \\
\hline phosphonoformate & 11.6 & - \\
\hline sulfate & - & 46.1 \\
\hline solvent & 28.0 & 30.5 \\
\hline
\end{tabular}

summary of the data collection and processing statistics is presented in Table 1 .

Crystals grown in the presence of product 2 were obtained from buffered [100 mM MES (pH 6.5)] $1.8 \mathrm{M}$ ammonium sulfate at $25{ }^{\circ} \mathrm{C}$. Data were collected at $-160{ }^{\circ} \mathrm{C}$ with a Rigaku RU200H source equipped with Yale mirrors and a RaxisIV imaging plate diffractometer. The data were processed with SCALEPACK and DENZO.

Crystallographic Refinement. Structure refinement calculations for the phosphonoformate complex were carried out with SHELXL (28). The structure of the phosphate complex at $1.35 \AA$ resolution (PDB entry $1 \mathrm{LQK}$ ) was used for an initial round of rigid body refinement giving an $R_{\text {work }}$ of $38.0 \%$ and an $R_{\text {free }}$ of $37.5 \%$. SHELXL was then used for a round of water divining, followed by several cycles of manual water addition and removal, the placement of residues with alternate conformations, and the placement of the inhibitor in the model, giving an $R_{\text {work }}$ of $20.0 \%$ and an $R_{\text {free }}$ of $22.4 \%$. A final round of refinement with anisotropic temperature factors and riding hydrogen atoms resulted in an $R_{\text {work }}$ of $13.3 \%$ and an $R_{\text {free }}$ of $16.1 \%$. The statistics for validation of the final model are given in Table 1 .

The structure of the protein from the ammonium sulfate crystal form had significantly different unit cell dimensions and was phased by molecular replacement. The starting 
<smiles>O=C([O-])P(=O)(O)O</smiles><smiles>O=C([O-])CP(=O)(O)O</smiles>
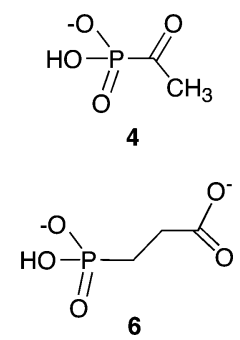

FIGURE 3: Inhibitors used in this study. For phosphonoformate (3), $K_{\mathrm{i}}=0.41 \pm 0.09 \mu \mathrm{M}$. For acetylphosphonate (4), $K_{\mathrm{i}}=18 \pm 2$ $\mu \mathrm{M}$. For phosphonoacetate $(5), K_{\mathrm{i}}=10 \pm 1 \mu \mathrm{M}$. For 2-carboxyethylphosphonate $(6), K_{\mathrm{i}}>100 \mu \mathrm{M}$.

model consisted of the PA1129 FosA stripped of all nonprotein atoms. MOLREP (29) was then used to orient the model in the ammonium sulfate crystal form. This gave an initial $R_{\text {crys }}$ of $37 \%$ and a correlation coefficient of 0.65 , indicating the search was successful. To reduce model bias, the new model was run through a round of simulated annealing in CNS (30), giving an $R_{\text {crys }}$ of $30 \%$ and an $R_{\text {free }}$ of $35 \%$. Inspection of the active site indicated that no product was present; instead, there was a sulfate ion coordinated to the $\mathrm{Mn}(\mathrm{II})$ center. The model was iteratively refined using $O$ (31) for visualization and model adjustment and REFMAC (32) for refinement. The Mn(II) ions, sulfate ions, and water molecules [added automatically with APR/warp (33)] were included in the subsequent rounds of refinement. Data collection and final refinement statistics are given in Table 1.

\section{RESULTS}

Inhibition of FosA with Simple Phosphonates. The original crystal structure of FosA (19) in the presence of $\mathbf{1}$ revealed extensive interactions between the phosphonyl group of fosfomycin and the active site, including coordination to the Mn(II) center and electrostatic or hydrogen bonding interactions with K40, S94, Y100, R119, and the $\mathrm{K}^{+}$ion, suggesting that simple phosphonates might be effective competitive inhibitors against fosfomycin. This notion was confirmed by a survey of several such molecules shown in Figure 3. The inhibition results appear to correlate with the geometry and electrostatics that are necessary for optimum formation of a bidentate chelate complex with the metal. The most avid inhibitor, $\mathbf{3}$, also more closely resembles the proposed early transition state for the reaction illustrated in Figure 2. Compound $\mathbf{3}$ is also a good inhibitor of the plasmid-encoded FosA (Tn2921) with a $K_{\mathrm{i}}$ of $0.69 \pm 0.08 \mu \mathrm{M}$.

Kinetics of Binding of Fosfomycin and Phosphonoformate. The binding of $\mathbf{1}$ or $\mathbf{3}$ to the FosA·Mn(II) complex is accompanied by similar but distinct spectral changes in the protein as illustrated in Figure 4A. The spectral differences were exploited in an effort to obtain kinetic information about the binding of substrate and inhibitor. Although initial experiments indicated that the sum of the on and off rates for $\mathbf{1}$ or $\mathbf{3}$ was too large to be directly measured by rapid mixing techniques, it was possible to exploit the difference in the $\Delta \epsilon_{245}$ values for the two complexes to obtain the $k_{\text {off }}$ for 3 from the FosA $\cdot \mathrm{Mn}(\mathrm{II}) \cdot \mathrm{K}^{+} \cdot \mathbf{3}$ complex and the $k_{\text {off }}$ for $\mathbf{1}$ from the FosA $\cdot \mathrm{Mn}(\mathrm{II}) \cdot \mathrm{K}^{+} \cdot \mathbf{1}$ complex. When the preformed FosA $\cdot \mathrm{Mn}(\mathrm{II}) \cdot \mathrm{K}^{+} \cdot \mathbf{3}$ complex was rapidly mixed with a large excess of $\mathbf{1}$, the kinetics for formation of the FosA $\cdot \mathrm{Mn}(\mathrm{II}) \cdot$ $\mathrm{K}^{+} \cdot \mathbf{1}$ complex could be followed by the increase in absor-
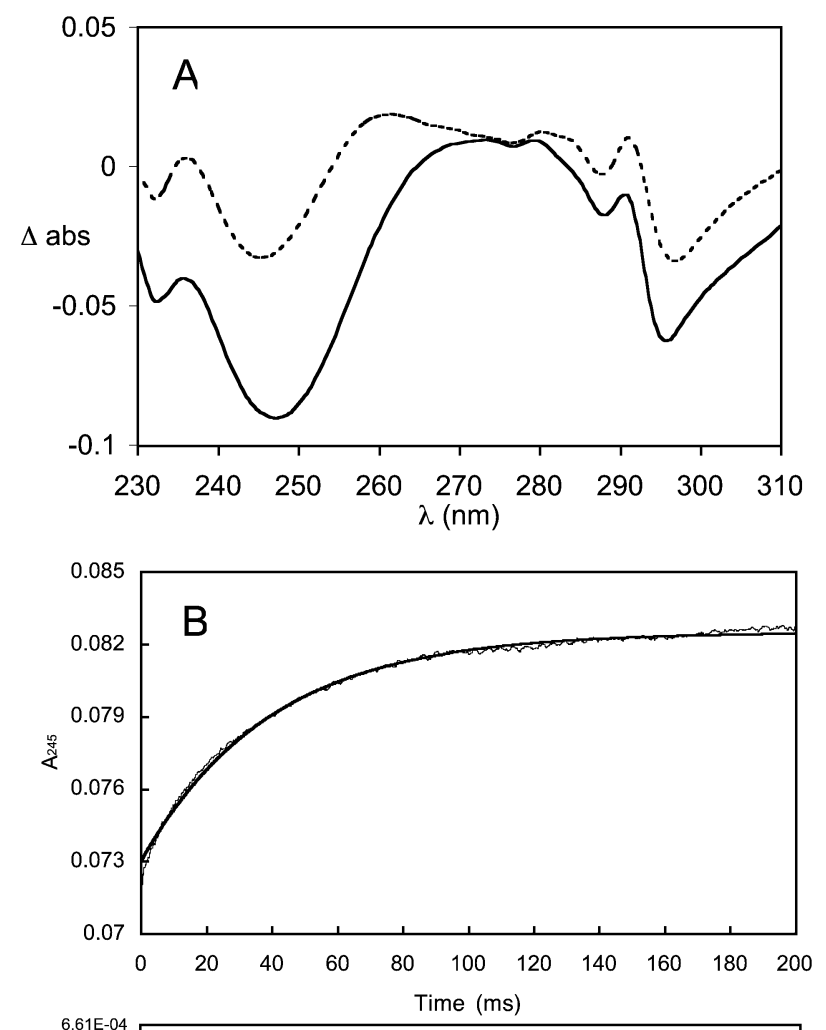

$-6.61 \mathrm{E}-04$

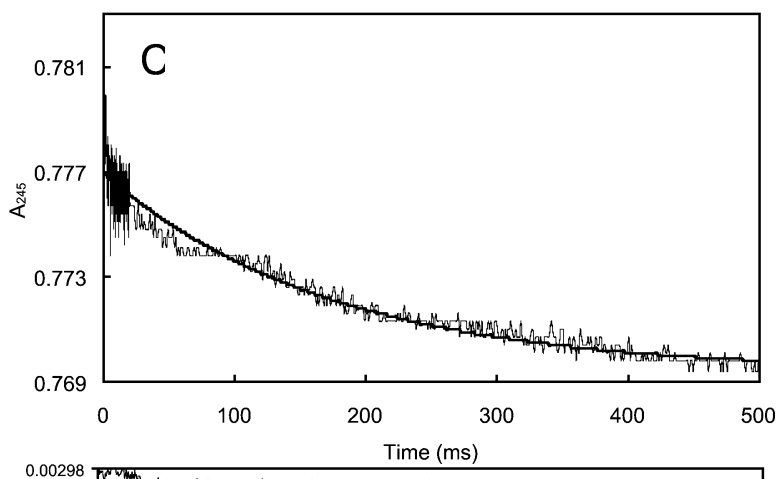

-0.00298

FIGURE 4: (A) UV difference spectra of the complexes: (- - ) FosA $\cdot \operatorname{Mn}(\mathrm{II}) \cdot 2-$ FosA $\cdot \operatorname{Mn}(\mathrm{II})\left(\Delta \epsilon_{245}=-1690 \mathrm{M}^{-1} \mathrm{~cm}^{-1}\right)$ and (一) FosA $\cdot \mathrm{Mn}(\mathrm{II}) \cdot 3-$ FosA $\cdot \mathrm{Mn}(\mathrm{II})\left(\Delta \epsilon_{245}=-4560 \mathrm{M}^{-1} \mathrm{~cm}^{-1}\right)$. (B) Change in $A_{245}$ on rapid mixing of $5 \mu \mathrm{M}$ FosA $\cdot \mathrm{Mn}(\mathrm{II}) \cdot \mathrm{K}^{+} \cdot \mathbf{3}$ with $10 \mathrm{mM}$ fosfomycin. The solid line is a fit of the data to a single-exponential equation with a $k_{\mathrm{obs}}$ of $5.06 \pm 0.02 \mathrm{~s}^{-1}$. The bottom trace is the residual to the fit. (C) Change in $A_{245}$ upon rapid mixing of the $\mathrm{Fos} A \cdot \mathrm{Mn}(\mathrm{II}) \cdot \mathrm{K}^{+} \cdot \mathbf{1}$ complex with $5 \mathrm{mM}$ phosphonoformate. The solid line is a fit of the data to a singleexponential equation with a $k_{\mathrm{obs}}$ of $29 \pm 3 \mathrm{~s}^{-1}$. The bottom trace is the residual to the fit.

bance at $245 \mathrm{~nm}$ as illustrated in Figure 4B. The formation of the $\mathrm{Fos} A \cdot \mathrm{Mn}(\mathrm{II}) \cdot \mathrm{K}^{+} \cdot \mathbf{1}$ complex followed single-exponential kinetics with a $k_{\mathrm{obs}}$ of $5 \mathrm{~s}^{-1}$ that was independent of 1 concentration between 5 and $20 \mathrm{mM}$. The kinetic behavior is consistent with the rapid trapping, by $\mathbf{1}$, of the ternary FosA $\cdot \mathrm{Mn}(\mathrm{II}) \cdot \mathrm{K}^{+}$complex formed upon dissociation of $\mathbf{3}$. The reciprocal experiment in which the $\mathrm{FosA} \cdot \mathrm{Mn}(\mathrm{II}) \cdot \mathrm{K}^{+} \cdot \mathbf{1}$ complex was rapidly mixed with a high concentration of $\mathbf{3}$ was accompanied as expected by a rapid decrease in absorbance at $245 \mathrm{~nm}$ with a $k_{\mathrm{obs}}$ of $30 \mathrm{~s}^{-1}$ (Figure 4C). 

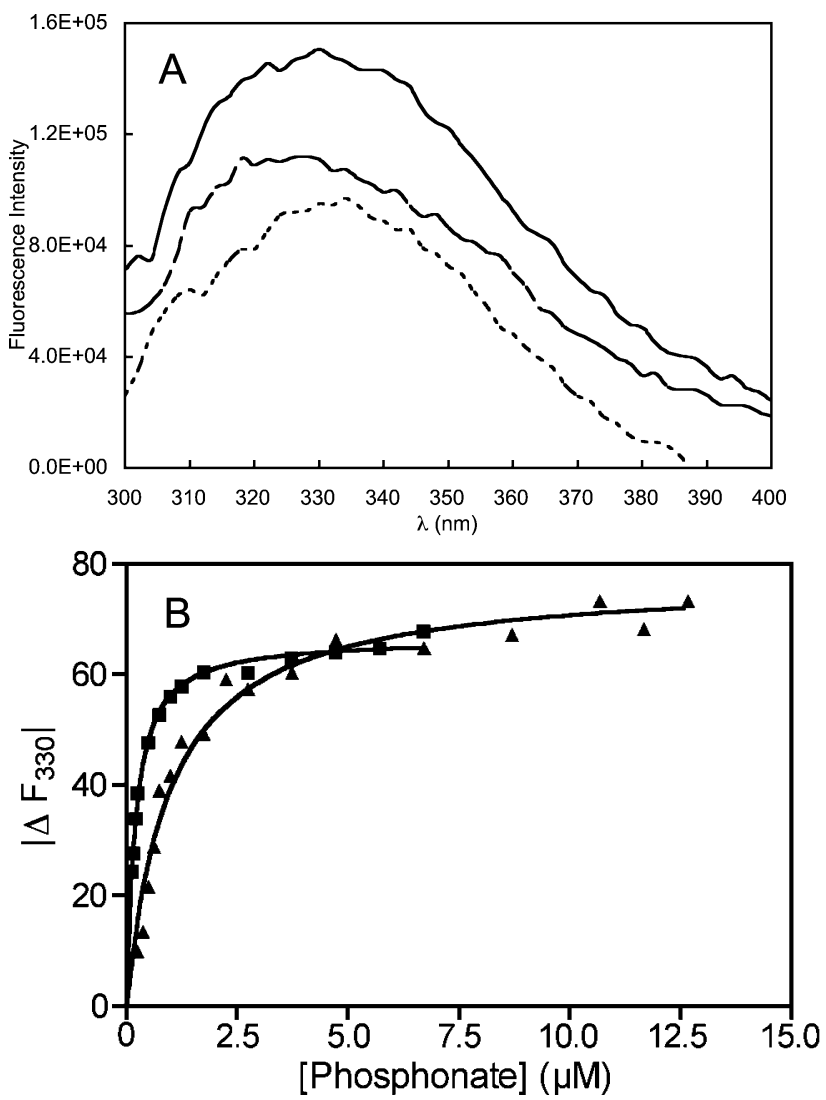

FIGURE 5: (A) Fluorescence emission spectra of the FosA $\cdot \mathrm{Mn}(\mathrm{II}) \cdot$ $\mathrm{K}^{+}(-)$, FosA $\cdot \mathrm{Mn}(\mathrm{II}) \cdot \mathrm{K}^{+} \cdot \mathbf{1}(---)$, and FosA $\cdot \mathrm{Mn}(\mathrm{II}) \cdot \mathrm{K}^{+} \cdot \mathbf{3}(---$ ) complexes with excitation at $275 \mathrm{~nm}$. (B) Fluorescence titrations of the FosA·Mn(II) complex (A) and $\mathbf{3}$ (ם). The solid lines are fits of the data to eq 1 with dissociation constants of $0.74 \pm 0.01 \mu \mathrm{M}$ for 1 and $0.17 \pm 0.01 \mu \mathrm{M}$ for $\mathbf{3}$.

In principle, the changes in the UV spectra of the complexes could be exploited to obtain equilibrium dissociation constants for $\mathbf{1}$ and $\mathbf{3}$. Unfortunately, the concentrations of enzyme required for monitoring titrations in the UV were in excess of the estimated $K_{\mathrm{d}}$ values for the complexes. However, the complexes were also found to have significant differences in their fluorescence spectra as illustrated in Figure $5 \mathrm{~A}$. The FosA $\cdot \mathrm{Mn}(\mathrm{II}) \cdot \mathrm{K}^{+} \cdot \mathbf{1}$ complex exhibits a $37 \%$ decrease in fluorescence at $330 \mathrm{~nm}$ when compared to the Fos $\mathrm{A} \cdot \mathrm{Mn}(\mathrm{II}) \cdot \mathrm{K}^{+}$complex. In addition, the FosA $\cdot \mathrm{Mn}(\mathrm{II}) \cdot \mathrm{K}^{+}$• 3 complex exhibits a blue shift of the emission band to 326 $\mathrm{nm}$.

The fluorescence titrations of the FosA $\cdot \mathrm{Mn}(\mathrm{II}) \cdot \mathrm{K}^{+}$complex with 1 and 3 at a low concentration $(0.1 \mu \mathrm{M})$ of the protein are illustrated in Figure 5B. The extracted estimates of the $K_{\mathrm{d}}$ values indicate that, in the absence of GSH, 3 binds only $\sim 4$-fold more tightly than the substrate. The $K_{\mathrm{d}}$ value of $0.2 \mu \mathrm{M}$ for 3 is in reasonable agreement with the $K_{\mathrm{i}}$ of $0.4 \mu \mathrm{M}$ obtained in the inhibition experiments.

High-Resolution Structure of the Inhibitor Complex. The high-resolution structure of the FosA·Mn(II) 3 inhibitor complex is quite similar to that of the substrate complex previously determined, with an rmsd on $\mathrm{C} \alpha$ positions of 0.29 $\AA$. The electron density of the inhibitor reveals that it forms a tight bidentate chelate complex with the $\mathrm{Mn}$ (II) center (Figure 6) with very good trigonal bipyramidal geometry. The angular structural parameter for describing trigonality is high ( $\tau=0.92)$, where a perfect trigonal bipyramid has a $\tau$ of 1.0 (34). The two histidine ligands from the protein and a phosphonate oxygen from the inhibitor occupy the equatorial positions, while the glutamate and the carboxylate group of $\mathbf{3}$ are axial ligands. The principal difference in the coordination geometry of the substrate and inhibitor complexes is the $\mathrm{Mn}(\mathrm{II})-\mathrm{O}$ distance between the neutral oxirane oxygen ligand in the substrate complex as shown in Figure 7.

The side chains of four residues (T9, S94, Y100, and R119) participate in binding both inhibitor and substrate as illustrated in Figure 8. The only significant difference in the structure of the protein in the substrate and inhibitor complexes is the position of Y62, which is pointed away from fosfomycin in the substrate complex and swings toward phosphonoformate in the inhibitor complex where its hydroxyl group is within hydrogen bonding distance $(2.58 \AA$ ) of the phosphonyl group of $\mathbf{3}$. The hydroxyl group of Y62 in the substrate complex is within hydrogen bonding distance of two water molecules. The recruitment of Y62 to interact directly with the inhibitor may be a consequence of additional negative charge in the complex. It is possible that the difference in the position of Y62 in the two complexes gives rise, at least in part, to their different spectral properties in the UV.

Structure of FosA Crystallized from Ammonium Sulfate. The second crystal form of FosA obtained from ammonium sulfate was determined at a resolution of $2.25 \AA$. The overall structure is quite close to that of the FosA $\cdot \mathrm{Mn}$ (II) $\mathbf{1}$ complex with an rmsd on $C \alpha$ positions of $0.47 \AA$. Crystal lattice contacts in this crystal form do not appear to block the approach to the active site. However, electron density maps for crystals grown in the presence of either GSH or the product, 2, showed no electron density that could be
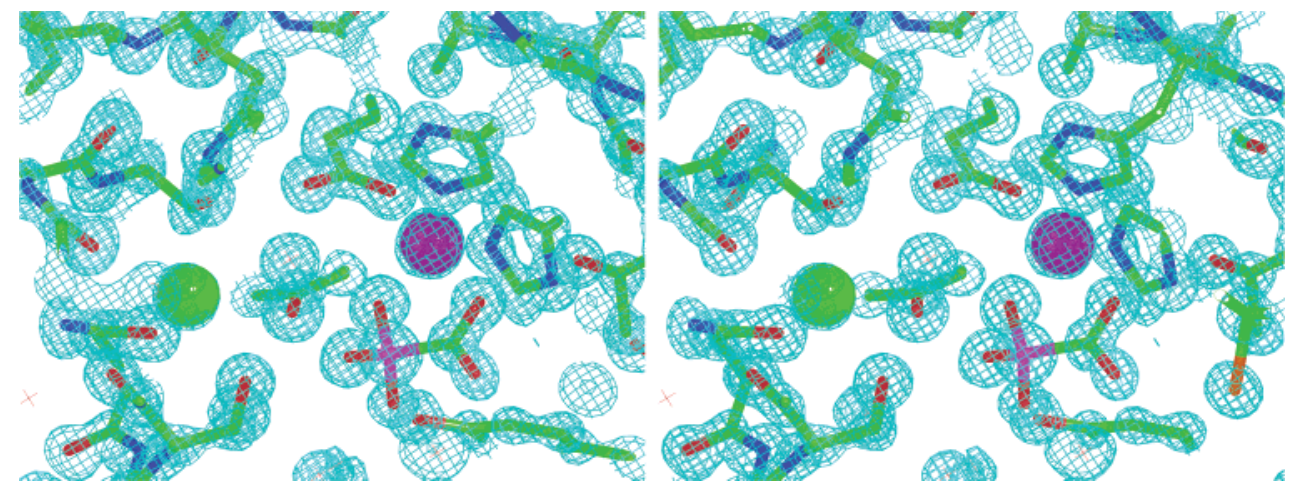

FIGURE 6: Stereoview of the $2 F_{\mathrm{o}}-F_{\mathrm{c}}$ electron density map of the FosA $\cdot \mathrm{Mn}(\mathrm{II}) \cdot \mathbf{3}$ complex at $0.95 \AA$ resolution and contoured at $2 \sigma$. The $\mathrm{Mn}(\mathrm{II})$ and $\mathrm{K}^{+}$ions are shown as purple and green spheres, respectively. The figure was generated with PyMOL (21). 

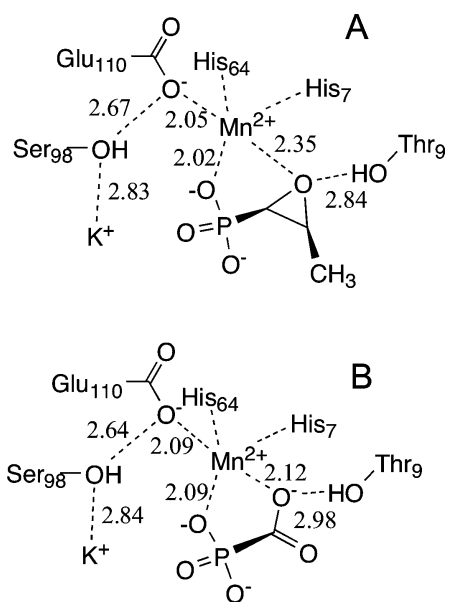

FIGURE 7: Internuclear distances in angstroms between heavy atoms in (A) the FosA $\cdot \mathrm{Mn}(\mathrm{II}) \cdot \mathbf{1}$ complex and (B) the FosA $\cdot \mathrm{Mn}(\mathrm{II}) \cdot \mathbf{3}$ complex.

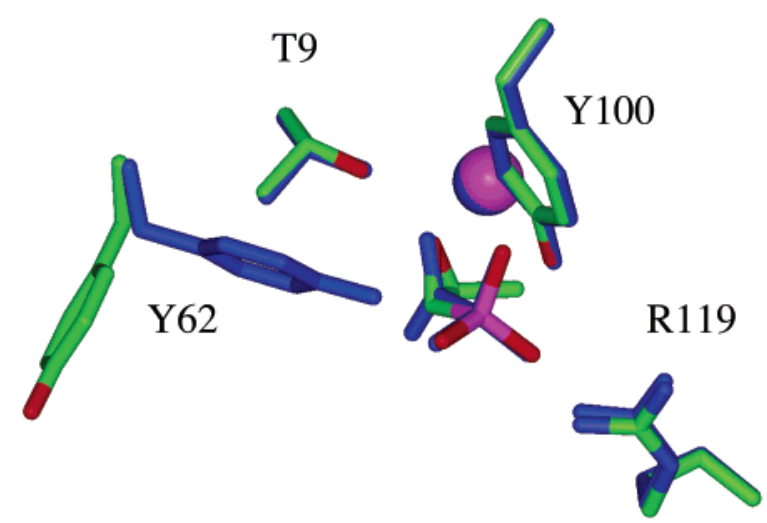

FIGURE 8: Local superposition of the FosA $\cdot \mathrm{Mn}(\mathrm{II}) \cdot 3$ complex (blue) with the substrate FosA $\cdot \mathrm{Mn}(\mathrm{II}) \cdot \mathbf{1}$ complex. The superposition was done using only the positions of the $\mathrm{Mn}$ (II) and protein ligands $\mathrm{H} 7, \mathrm{H64}$, and E110 (not shown). S94, which is also within hydrogen bonding distance of the phosphonyl group, is not shown for clarity. Note the repositioning of the Y62 side chain in the inhibitor complex.

attributed to these species. Rather, a sulfate ion is found coordinated to the $\mathrm{Mn}$ (II) center at a position very close to that occupied by the phosphonyl group in the structures of the FosA $\cdot \mathrm{Mn}(\mathrm{II}) \cdot \mathbf{1}$ and FosA $\cdot \mathrm{Mn}(\mathrm{II}) \cdot \mathbf{3}$ complexes (Figure 9). In addition, the $\mathrm{K}^{+}$loop in this structure is occupied by $\mathrm{NH}_{4}{ }^{+}$, which is also known to activate the enzyme (16). It appears that the high concentration of $\left(\mathrm{NH}_{4}\right)_{2} \mathrm{SO}_{4}$ prevents formation of the substrate or product complexes.

The Mn(II) ion in this structure is four-coordinate with a highly distorted tetrahedral geometry that was previously observed in a phosphate complex (19). Each oxygen of the sulfate ion has hydrogen bonding or electrostatic interactions with neighboring groups, including the $\mathrm{Mn}(\mathrm{II})$ ion, the hydroxyl groups of Y62 and S94, and water molecules that bridge the hydroxyl group of Y39 and the carboxylate of E110.

\section{DISCUSSION}

Coordination Geometry of Mn(II) and Mechanism of FosA. The $\mathrm{Mn}(\mathrm{II})$ centers of the phosphate (19) and sulfate complexes of FosA exhibit a rarely observed four-coordinate geometry where the tetrahedral anions occupy the site that accommodates the phosphonyl groups of $\mathbf{1}$ and $\mathbf{3}$. It is

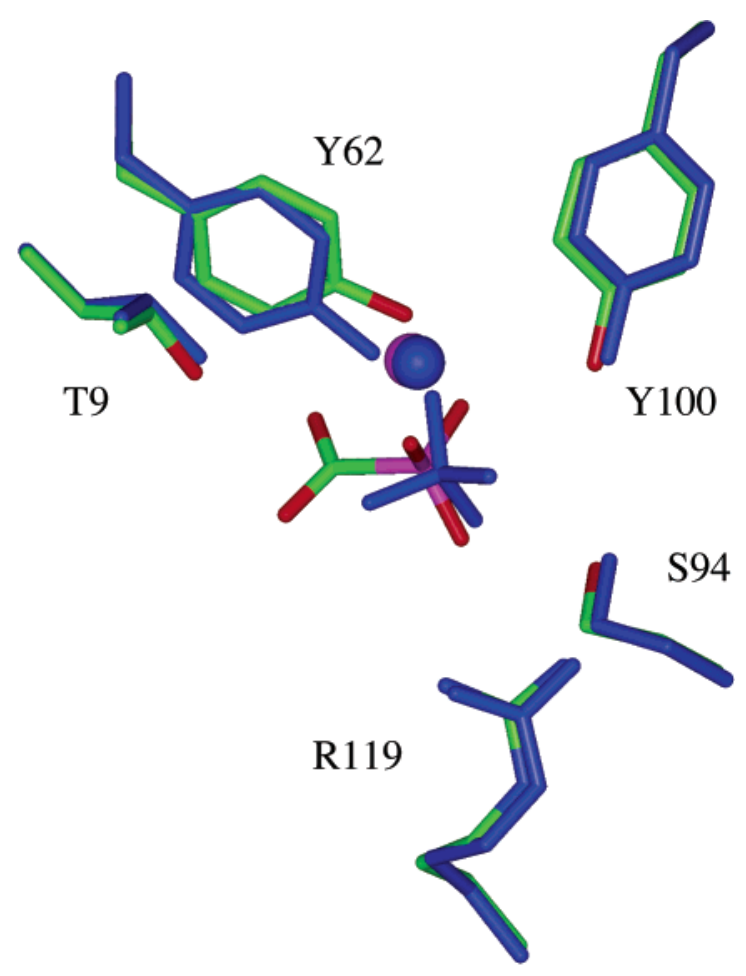

FIGURE 9: Local superposition of the structures of the sulfate (blue) and phosphonoformate complexes of FosA. The superposition was done using the $\mathrm{Mn}(\mathrm{II})$ positions and metal ligands from the protein [H7, H64, and E110 (not shown)]. The displacement of the sulfur of the sulfate from the position of the phosphorus in 3 is $0.4 \AA$.

interesting to note that a sulfate ion is observed at the same position in the crystal structure of the plasmid-encoded (Tn2921) apoFosA obtained in the absence of Mn(II) (35). Thus, a tetrahedral anion binding site exists even in the absence of metal. The substrate complex approaches a fivecoordinate trigonal bipyramidal geometry with the oxirane oxygen $\sim 0.2 \AA$ farther from the metal than might be expected for a neutral oxygen ligand. In contrast, the phosphonoformate complex has almost perfect trigonal bipyramidal geometry. We conclude that the primary determinants of substrate recognition are the interactions developed between the phosphonyl group of $\mathbf{1}$ and the enzyme, including the $\mathrm{Mn}(\mathrm{II})$ and $\mathrm{K}^{+}$ions. Recognition of the transition state appears to be driven by the change to a more favorable fivecoordinate geometry of the $\mathrm{Mn}(\mathrm{II})$ center.

Kinetics of Binding Fosfomycin and Phosphonoformate. The dissociation constant of $0.2 \mu \mathrm{M}$ and $k_{\text {off }}$ of $5 \mathrm{~s}^{-1}$ suggest that the binding of $\mathbf{3}$ occurs near the diffusion limit; $k_{\mathrm{on}}=$ $k_{\text {off }} / K_{\mathrm{d}} \approx 10^{7}-10^{8} \mathrm{M}^{-1} \mathrm{~s}^{-1}$. The $k_{\text {off }}$ of $30 \mathrm{~s}^{-1}$ and the $K_{\mathrm{d}}$ of $0.7 \mu \mathrm{M}$ are consistent with a diffusion-controlled binding of $\mathbf{1}$ as well. The one clearly measurable difference in the equilibrium binding of $\mathbf{3}$ is the smaller rate constant for dissociation of the bidentate chelate.

Inhibition of FosA by Phosphonates. Several simple phosphonates are modestly effective inhibitors of the FosA enzyme encoded in the genome of $P$. aeruginosa. Compounds $\mathbf{3}-\mathbf{5}$ were chosen as possible transition state analogues of the addition reaction based on the original suggestion that the $\mathrm{Mn}(\mathrm{II})$ center acts as a Lewis acid to facilitate breaking of the $\mathrm{C}-\mathrm{O}$ bond of the oxirane $(14,19)$. Oxirane ring opening reactions typically occur with early transition states so that the geometry of the proposed fivemembered chelate ring (Figure 2B) is very close to that 
observed in the complex with $\mathbf{3}$. Moreover, it is evident from the superposition of the fosfomycin and phosphonoformate structures (Figure 7) that the carboxylate oxygen of the inhibitor and the oxirane oxygen of the substrate occupy nearly the same position. Phosphonoacetate, 5, with the chelate ring expanded by a methylene group, binds $\sim 20$ fold less tightly than 3 . This compound resembles the structure of a very late transition state (Figure 2B) in which the $\mathrm{C}-\mathrm{O}$ bond is almost completely broken.

Transition state analogue inhibitors typically bind much more tightly than the corresponding substrate does. The fact that 3 binds only $\sim 6$-fold more tightly than $\mathbf{1}$ may reflect the fact that the reaction has a very early transition state with little charge build-up on the oxirane oxygen. Taken together, these observations suggest that $\mathbf{3}$ can be viewed as a minimal transition state inhibitor for FosA given that it lacks any of the structural elements of the second substrate GSH.

Acetylphosphonate, $\mathbf{4}$, with a neutral oxygen adjacent to the phosphonyl group, has a $K_{\mathrm{i}}$ that is significantly higher than the $K_{\mathrm{d}}$ for fosfomycin. This compound is of particular interest because of its potential to form an enolate complex, 7, or a metal-stabilized 1,2-adduct with GSH, 8.
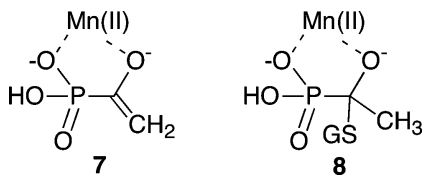

The FosA $\cdot \mathrm{Mn}(\mathrm{II})$ complex does not catalyze exchange of the methyl protons of $\mathbf{4}$ in $\mathrm{D}_{2} \mathrm{O}$ (data not shown), suggesting that the enzyme does not promote enolate formation over and above that observed with $\mathrm{Mn}(\mathrm{II}) \cdot 6 \mathrm{H}_{2} \mathrm{O}$. Inasmuch as 4 is not a very good inhibitor, it is unlikely that $\mathbf{8}$, if formed on the enzyme, is a particularly stable or highly populated species.

Escherichia coli transformed with the expression plasmid for FosA exhibit robust resistance to fosfomycin. Unfortunately, none of the inhibitors examined here were effective in enhancing the efficacy of fosfomycin toward these transformants either in liquid culture or on agar plates. The reason for the lack of activity in vivo is unclear but may be due to ineffective transport of the molecules into the cytosol of the bacterium.

Conclusions. The results reported here establish a stereoelectronic basis for the design of effective inhibitors of fosfomycin resistance proteins. The development of inhibitors that are effective in vivo is an attractive avenue for enhancing the efficacy of fosfomycin toward pathogens that harbor either plasmid or genomically encoded resistance proteins.

\section{ACKNOWLEDGMENT}

Use of the Advanced Photon Source was supported by the U.S. Department of Energy, Basic Energy Sciences, Office of Science, under Contract W-31-109-Eng-38. Use of the BioCARS Sector 14 was supported by the National Institutes of Health, National Center for Research Resources, under Grant RR07707.

\section{REFERENCES}

1. Hendlin, D., Stapley, E. O., Jackson, M., Wallick, H., Miller, A. K., Wolf, F. J., Miller, T. W., Chaiet, L., Kahan, F. M., Flotz, E. L., Woodruff, H. B., Mata, J. M., Hernandez, S., and Mochales,
S. (1969) Phosphonomycin, a new antibiotic produced by strains of Streptomyces, Science 166, 122-123.

2. Christensen, B. G., Leanza, W. J., Beattie, T. R., Patchett, A. A., Arison, B. H., Ormond, R. E., Kuehl, F. A., Albers-Schonberg, G., and Jardetzky, O. (1969) Phosphonomycin: structure and synthesis, Science 166, 123-124.

3. Kahan, F. M., Kahan, J. S., Cassidy, P. J., and Kroop, H. (1974) The mechanism of action of fosfomycin (phosphonomycin), Ann. N.Y. Acad. Sci. 235, 364-385.

4. Marquardt, J. L., Brown, E. D., Lane, W. S., Haley, T. M., Ichskawa, Y., Wong, C.-H., and Walsh, C. T. (1994) Kinetics, stoichiometry, and identification of the reactive thiolate in the inactivation of UDP-GlcNAc enolpyruvoyl transferase by the antibiotic fosfomycin, Biochemistry 33, 10646-10651.

5. Skarzynski, T., Mistry, A., Wonacott, A., Hutchinson, S. E., Kelly, V. A., and Duncan, K. (1996) Structure of UDP- $N$-acetylglucosamine enolpyruvyl transferase, an enzyme essential for the synthesis of bacterial peptidoglycan, complexed with substrate UDP- $N$-acetylglucosamine and the drug fosfomycin, Structure 4, $1465-1474$.

6. Patel, S. S., Balfour, J. A., and Bryson, H. M. (1997) Fosfomycin tromethamin. A review of its antibacterial activity, pharmacokinetic properties and therapeutic efficacy as a single-dose oral treatment for acute uncomplicated lower urinary tract infections, Drugs 53, 637-656.

7. Krcmery, S., Hromec, J., and Demesova, D. (2001) Treatment of lower urinary tract infection in pregnancy, Int. J. Antimicrob. Agents 17, 279-282.

8. Allerberger, F., and Klare, I. (1999) In-vitro activity of fosfomycin against vancomycin-resistant enterococci, J. Antimicrob. Chemoth er. 43, 211-217.

9. Mendoza, M. C., Garcia, J. M., Llaneza, J., Mendez, J. F., Hardisson, C., and Ortiz, J. M. (1980) Plasmid determined resistance to fosfomycin in Serratia marcescens, Antimicrob. Agents Chemother. 18, 215-219.

10. Llaneza, J., Villar, C. J., Salas, J. A., Suarez, J. E., Mendoza, M. C., and Hardisson, C. (1985) Plasmid-mediated fosfomycin resistance is due to enzymatic modification of the antibiotic, Antimicrob. Agents Chemother. 28, 163-164.

11. Villar, C. J., Hardisson, C., and Suarez, J. E. (1986) Cloning and molecular epidemiology of plasmid-determined fosfomycin resistance, Antimicrob. Agents Chemother. 29, 309-314.

12. Arca, P., Rico, M., Brana, A. F., Villar, C. J., Hardisson, C., and Suarez, J. E. (1988) Formation of an adduct between fosfomycin and glutathione: a new mechanism of antibiotic resistance in bacteria, Antimicrob. Agents Chemother. 32, 1552-1556.

13. Arca, P., Hardisson, C., and Suarez, J. E. (1990) Purification of a glutathione $S$-transferase that mediates fosfomycin resistance in bacteria, Antimicrob. Agents Chemother. 34, 844-848.

14. Bernat, B. A., Laughlin, L. T., and Armstrong, R. N. (1997) Fosfomycin resistance protein (FosA) is a manganese metalloglutathione transferase related to glyoxalase I and the extradiol dioxygenases, Biochemistry 36, 3050-3055.

15. Bernat, B. A., Laughlin, L. T., and Armstrong, R. N. (1998) Regiochemical and stereochemical course of the reaction catalyzed by the fosfomycin resistance protein, FosA, J. Org. Chem. 63, $3778-3780$.

16. Bernat, B. A., Laughlin, L. T., and Armstrong, R. N. (1999) Elucidation of a monovalent cation dependence and characterization of the divalent cation binding site of the fosfomycin resistance protein, FosA, Biochemistry 38, 7462-7469.

17. Bergdoll, M., Eltis, L. D., Cameron, A. D., Dumas, P., and Bolin, J. T. (1998) All in the family: structural and evolutionary relationships among three modular proteins with diverse functions and variable assembly, Protein Sci. 7, 1661-1670.

18. Armstrong, R. N. (2000) Mechanistic Diversity in a Metalloenzyme Superfamily, Biochemistry 39, 13625-13632.

19. Rife, C. L., Pharris, R. E., Newcomer, M. E., and Armstrong, R. N. (2002) Crystal structure of a genomically encoded fosfomycin resistance protein (FosA) at $1.19 \AA$ resolution by MAD phasing off the L-III edge of $\mathrm{Tl}^{+}, \mathrm{J}$. Am. Chem. Soc. 124, 11001-11003.

20. Cao, M., Bernat, B. A., Wang, Z., Armstrong, R. N., and Helmann, J. D. (2001) FosB, a cysteine-dependent fosfomycin resistance protein under the control of $\sigma \mathrm{W}$, an extracytoplasmic function $\sigma$ factor in Bacillus subtilis, J. Bacteriol. 183, 2380-2383.

21. DeLano, W. L. (2002) PyMOL Molecular Graphics System (http://www.pymol.org) 
22. Bernat, B. A., and Armstrong, R. N. (2001) Elementary steps in the acquisition of $\mathrm{Mn}^{2+}$ by the fosfomycin resistance protein (FosA), Biochemistry 40, 12712-12718.

23. Smoukov, S., Telser, J., Bernat, B. A., Rife, C. L., Armstrong, R. N., and Hoffman, B. M. (2002) EPR evidence for the interaction between substrates and the $\mathrm{Mn}(\mathrm{II})$ active site of the bacterial antibiotic resistance enzyme, FosA: A better way to examine Mn(II), J. Am. Chem. Soc. 124, 2208-2217.

24. McConnell, R. L., and Coover, H. W., Jr. (1956) Preparation of 1-hydroxyalkylidenediphosphonates, J. Am. Chem. Soc. 78, 44504452.

25. Sekine, M., and Hata, T. (1978) Convenient Synthesis of Unesterified Acylphosphonic Acids, J. Chem. Soc., Chem. Commun. 7, 285-286.

26. Dixon, M. (1953) The determination of enzyme inhibitor constants, Biochem. J. 55, 170-171.

27. Otwinowski, Z., and Minor, W. (1997) Processing of X-ray diffraction data collected in oscillation mode, Methods Enzymol. 276, 307-326.

28. Sheldrick, G. M., and Schneider, T. R. (1997) SHELXL: Highresolution refinement, Methods Enzymol. 277, 319-343.

29. Vagin, A., and Teplyakov, A. (2000) An approach to multi-copy search in molecular replacement, Acta Crystallogr. D56, 16221624.
30. Brünger, A. T., Adams, P. D., Clore, G. M., DeLano, W. L., Gros, P., Grosse-Kunstleve, R. W., Jiang, J.-S., Kuszewski, J., Nilges, M., Pannu, N. S., Read, R. J., Rice, L. M., Simonson, T., and Warren, G. L. (1998) Crystallography \& NMR system: A new software suite for macromolecular structure determination, Acta Crystallogr. D54, 905-921.

31. Jones, T. A., Zou, J. Y., Cowan, S. W., and Kjeldgaard, M. (1991) Improved methods for building models in electron density map and the location of errors in these models, Acta Crystallogr. A47, $110-119$.

32. Collaborative Computational Project, Number 4 (1994) Acta Crystallogr. D50, 760.

33. Lamzin, V. S., and Wilson, K. S. (1997) Automated refinement for protein crystallography, Methods Enzymol. 277, 269-305.

34. Addison, A. W., Rao, T. N., Reedijk, J., van Rijn, J., and Verschoor, G. C. (1984) Synthesis, structure and spectroscopic properties of copper(II) compounds containing nitrogen-sulphur donor ligands; the crystal and molecular structure of aqua[1,7bis( $N$-methylbenzimidazol-2'-yl)-2,6-dithiaheptane]copper(II) perchlorate, J. Chem. Soc., Dalton Trans., 1349-1356.

35. Pakhomova, S., Rife, C. L., Armstrong, R. N., and Newcomer, M. E. (2004) The structure of fosfomycin resistance protein (FosA) from transposon Tn2921, Protein Sci. 13, 1260-1265.

BI048767H 